\title{
Liraglutide Reduces Visceral and Intrahepatic Fat Without Significant Loss of Muscle Mass in Obese Patients With Type 2 Diabetes: A Prospective Case Series
}

\author{
Satoshi Ishii ${ }^{a}$, Yoshio Nagai ${ }^{a}$, , Yukiyoshi Sada ${ }^{a}$, Hisashi Fukuda ${ }^{a}$, Yuta Nakamura ${ }^{a}$, \\ Ren Matsuba ${ }^{\text {a }}$, Tomoko Nakagawa ${ }^{\text {a }}$, Hiroyuki Kato ${ }^{\text {a }}$, Yasushi Tanaka ${ }^{\mathrm{a}}$
}

\begin{abstract}
Background: Glucagon-like peptide-1 receptor agonists have been reported to reduce body fat as well as improving glycemic control in obese patients with type 2 diabetes. However, the maximum dose of liraglutide is limited to $0.9 \mathrm{mg}$ in Japan, while the international dose is $1.8 \mathrm{mg}$; and the effect of this low dose on body composition has not been assessed in detail. Accordingly, this study was performed to evaluate the effect of liraglutide on body composition when administered at $0.9 \mathrm{mg}$ once daily for 24 weeks.
\end{abstract}

Methods: Nine patients were enrolled and started liraglutide at 0.3 $\mathrm{mg}$ once daily, which was titrated to $0.9 \mathrm{mg}$ once daily after 1 - 2 weeks and continued for 24 weeks. To comprehensively investigate changes of body composition, the body fat and muscle weight were determined by dual energy absorptiometry, visceral fat volume (VFV) and abdominal subcutaneous fat volume (SFV) were measured by abdominal computed tomography (CT), and the intrahepatic lipid content (IHL) was assessed by proton magnetic resonance spectroscopy. Measurements were obtained before starting liraglutide therapy and after 12 and 24 weeks of treatment.

Results: Fasting plasma glucose was significantly reduced from 127 \pm 22 to $101 \pm 14 \mathrm{mg} / \mathrm{dL}$ at 24 weeks and hemoglobin A1c (HbAlc) showed significant reduction from $6.4 \pm 0.9 \%$ to $5.2 \pm 0.5 \%$. Body weight was reduced from $103.4 \pm 14.7$ to $97.0 \pm 12.4 \mathrm{~kg}$ (mean reduction: $11.7 \%$ ) and BMI decreased from $37.4 \pm 6.4$ to $35.0 \pm 5.3 \mathrm{~kg} / \mathrm{m}^{2}$ (mean reduction: $5.8 \%$ ). Furthermore, VFV and IHL decreased from $5,192 \pm 1,730$ to $4,513 \pm 1,299 \mathrm{~cm}^{3}$ (mean reduction: $11.9 \%$ ) and $32.1 \pm 12.6 \%$ to $15.2 \pm 9.2 \%$ (mean reduction: $49.2 \%$ ), respectively, but SFV did not change. Moreover, the fat index was reduced from 14.8 \pm 4.4 to $12.9 \pm 3.4 \mathrm{~kg} / \mathrm{m}^{2}$ (mean reduction: $10.9 \%$ ), but the skeletal muscle index did not change.

Conclusions: In obese Japanese drug-naive patients who had type 2

Manuscript submitted January 11, 2019, accepted January 24, 2019

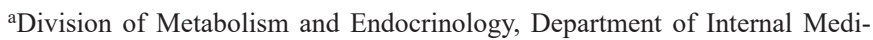
cine, St. Marianna University School of Medicine, Kawasaki, Japan ${ }^{b}$ Corresponding Author: Yoshio Nagai, 2-16-1, Sugao, Miyamae-ku, Kawasaki, Kanagawa 216-8511, Japan. Email: ynagai@marianna-u.ac.jp

doi: https://doi.org/10.14740/jocmr3647 diabetes, treatment with liraglutide ( $0.9 \mathrm{mg}$ once daily for 24 weeks) reduced body fat, especially visceral fat and intrahepatic fat, while having no significant effect on skeletal muscle.

Keywords: Liraglutide; Visceral fat volume; Subcutaneous fat volume; Intrahepatic lipid content; Skeletal muscle index

\section{Introduction}

Excess visceral fat in the abdomen and hepatic lipid accumulation are closely associated with insulin resistance and the metabolic syndrome [1,2], especially in obese patients with type 2 diabetes. In such patients, weight reduction by lifestyle modification, such as achieving the optimal dietary energy intake, is important for restoring insulin sensitivity and improving glycemic control. However, when obese persons succeed in losing weight, their muscle mass usually decreases along with body fat reduction [3]. The skeletal muscles handle about $40-45 \%$ of oral glucose intake, and account for up to $80-85 \%$ of insulinmediated glucose disposal $[4,5]$. Since the skeletal muscles represent the major site of glucose disposal, a decrease of skeletal muscle mass may be associated with deterioration of glucose metabolism in patients with type 2 diabetes. In addition, a decrease of the skeletal muscle mass may be associated with an increased risk of sarcopenia and frailty in elderly patients. Therefore, it is preferable to predominantly reduce fat without significant loss of muscle mass when weight loss is achieved.

Some antidiabetic agents, such as sodium-glucose cotransporter 2 (SGLT2) inhibitors and glucagon-like peptide-1 (GLP-1) receptor agonists (GLP-1RAs), potently promote weight loss and thus are widely used to treat obese patients with type 2 diabetes. Treatment with the SGLT2 inhibitor dapagliflozin $(10 \mathrm{mg} /$ day for 24 weeks) led to mean reduction of fat mass and lean mass by $2.2 \mathrm{~kg}$ and $1.1 \mathrm{~kg}$, respectively, as assessed by whole-body dual energy X-ray absorptiometry (DEXA) [6]. Recently, we used DEXA to examine the effect of treatment with the SGLT2 inhibitor ipragliflozin $(50 \mathrm{mg} /$ day for 24 weeks) in obese Japanese patients with type 2 diabetes, revealing mean reduction of fat mass and lean mass by $1.8 \mathrm{~kg}$ and $1.7 \mathrm{~kg}$, respectively [7]. These findings suggest that SGLT2 inhibitors may induce catabolism of both body fat and mus- 
cle secondary to energy loss through promotion of glycosuria. In the Liraglutide Effect and Action in Diabetes trial (LEAD-2), treatment with the GLP-1RA liraglutide (once daily injection of $0.6 \mathrm{mg}, 1.2 \mathrm{mg}$, or $1.8 \mathrm{mg}$ for 24 weeks) also resulted in significant reduction of both fat mass and lean mass as assessed by DEXA, but the LEAD-3 trial (once daily injection of $1.2 \mathrm{mg}$ or $1.8 \mathrm{mg}$ for 52 weeks) revealed no significant change of lean mass due to liraglutide despite marked reduction of body fat [8]. Recently, Perna et al reported significant reduction of fat mass, but not appendicular lean mass, in obese elderly patients receiving once-daily liraglutide for 24 weeks (initiated at $1.2 \mathrm{mg}$ and titrated to $3.0 \mathrm{mg}$ ) [9]. Furthermore, Blundell et al investigated the effect of a new onceweekly GLP-1RA (semaglutide, which has a similar structure to liraglutide) in obese patients with a BMI of 30 to $45 \mathrm{~kg} / \mathrm{m}^{2}$. After treatment for 12 weeks with dose escalation to $1.0 \mathrm{mg}$, they found mean reduction of body fat mass and lean mass by $3.5 \mathrm{~kg}$ and $1.1 \mathrm{~kg}$, respectively [10], and they also reported that the glucose-lowering effect of $0.4 \mathrm{mg}$ of semaglutide was equal to $1.2 \mathrm{mg}$ of liraglutide [11]. These results suggested that GLP-1RAs can reduce body fat with less effect on muscle than SGLT2 inhibitors, but the data were obtained by using higher doses in mainly obese Caucasian patients with type 2 diabetes. In Japan, the maximum daily dose of liraglutide is limited to $0.9 \mathrm{mg}$, and the influence of this lower dose of liraglutide on body composition has not been fully examined. Therefore, we performed a prospective case series study in drug-naive obese Japanese patients with type 2 diabetes to evaluate the effect of liraglutide ( $0.9 \mathrm{mg}$ once daily for 24 weeks) on body composition parameters, including visceral fat volume (VFV), subcutaneous fat volume (SFV), intrahepatic lipid content (IHL), body fat mass, and appendicular lean body mass.

\section{Materials and Methods}

\section{Patients}

We enrolled Japanese patients with type 2 diabetes attending the outpatient clinic of St. Marianna University Hospital (Kawasaki, Japan) between April 2013 and March 2016. The inclusion criteria were as follows: 1) Age of 20 - 70 years; 2) Overweight or obese (BMI $\geq 25 \mathrm{~kg} / \mathrm{m}^{2}$ ) and on treatment with diet alone; 3) Estimated duration of diabetes $<10$ years; 4) No previous use of insulin, GLP-1RAs, or other antidiabetic agents; 5) Hemoglobin A1c (HbA1c) of 5.0-9.0\% and showing variation by $<0.5 \%$ within 3 months before starting liraglutide therapy. The exclusion criteria were as follows: 1) A history of coronary artery disease, stroke, or peripheral artery disease; 2) Malignancy, severe renal disease (eGFR $<45 \mathrm{~mL} / \mathrm{min} / 1.73$ $\mathrm{m}^{2}$ ), or severe liver disease (AST and/or ALT $\geq 100 \mathrm{IU} / \mathrm{L}$ ); and 3) other patients considered to be unsuitable for this study by the attending doctors. This study was conducted in accordance with the ethical principles of the Declaration of Helsinki, and was approved by the ethics committee of St. Marianna University School of Medicine. Nine patients were enrolled and started treatment with liraglutide at $0.3 \mathrm{mg}$ once daily, which was titrated to $0.9 \mathrm{mg}$ once daily after $1-2$ weeks and contin- ued for at least 24 weeks.

\section{Assessment of body composition, visceral fat, and intrahe- patic lipid content}

Whole-body fat mass and lean mass were measured by DEXA (Lunar iDXA, GE Healthcare, Madison, WI, USA). The appendicular skeletal muscle index (SMI) was calculated as the lean mass of all four limbs divided by the height squared $\left(\mathrm{kg} / \mathrm{m}^{2}\right)$, and the fat index (FI) was calculated as the total fat mass divided by the height squared $\left(\mathrm{kg} / \mathrm{m}^{2}\right)$. Whole abdominal computed tomography (CT) scanning were performed with a 16-row multidetector CT device (Aquillion ${ }^{\mathrm{TM}}$ 16; Toshiba Medical Systems Co., Tokyo, Japan), using scanning conditions of $120 \mathrm{kV}, 250$ - $300 \mathrm{~mA}$, and $0.5 \mathrm{~s}$ rotation. The protocol involved acquisition of $700-800$ images with a slice thickness of $0.5 \mathrm{~mm}$ from the top of liver to the floor of the pelvic cavity. Adipose tissue was identified as the pixels ranging from -190 to -30 Hounsfield units. Imaging data were transferred to a workstation for analysis of the abdominal fat volume. Visceral fat volume (VFV) and subcutaneous fat volume (SFV) were calculated by using SYNAPSE VINCENT® software (Fuji Film, Tokyo, Japan) [12]. Proton magnetic resonance spectroscopy $\left({ }^{1} \mathrm{H}-\mathrm{MRS}\right)$ was performed as described previously [13]. Briefly, images of the liver were obtained with a 1.5-Tesla whole-body system (Intera Achieva; Phillips Medical Systems, Netherlands). The volume of interest $\left(20 \times 20 \times 20 \mathrm{~mm}^{3}\right)$ was centered on segment 6 of the liver, and spectra were acquired by using a point-resolved spectroscopy sequence (PRESS) with a repetition time (TR) of 2,000 ms, echo time (TE) of $144 \mathrm{~ms}$, and 128 acquisitions. Then intracellular triglycerides were quantified from the methylene proton peaks $\left(-\mathrm{CH}_{2}\right)$ of fatty acids at $1.3 \mathrm{ppm}$. Spectrum fitting and analysis were done with LC-Model software (version 6.2; S. Provencher, PhD, Canada), after which the IHL content was calculated as follows: area under the curve of the methylene proton peak (AUC-IHL)/(AUC-IHL + area under the water proton peak (AUC-water $) \times 100(\%)$. These assessments were performed before initiation of liraglutide treatment and after 12 and 24 weeks of treatment.

\section{Biochemical analysis}

Fasting blood samples were obtained before the start of liraglutide therapy and after 12 and 24 weeks of treatment. Plasma glucose, plasma insulin, and serum lipids (triglycerides, highdensity cholesterol (HDL-C), and low-density cholesterol (LDL-C)) were measured by the standard methods. HOMA-IR was calculated using the formula: fasting plasma glucose (mg/ $\mathrm{dL}) \times$ fasting plasma insulin $(\mathrm{U} / \mathrm{mL}) / 405$. HbA1c was determined by the latex cohesion method. All analyses were performed at the central laboratory of our hospital.

\section{Statistical analysis}

Results are expressed as the mean $\pm \mathrm{SD}$ or SE. Differences 
Table 1. Clinical Characteristics and Changes Of Variables

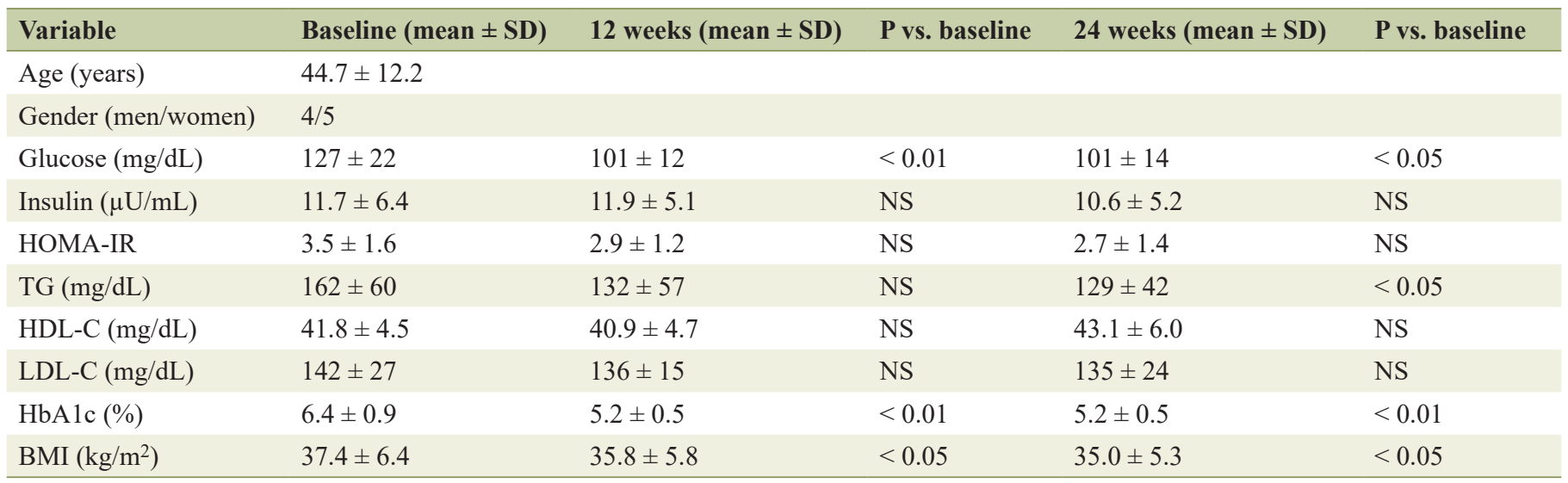

among variables measured before starting liraglutide treatment and after 12 and 24 weeks of treatment were assessed by twoway ANOVA. In all analyses, a probability of less than 0.05 was considered to indicate statistical significance.

\section{Results}

Clinical characteristics of the nine patients and the changes of variables are displayed in Table 1. While plasma glucose, serum triglycerides, $\mathrm{HbAlc}$, and BMI were significantly reduced after 24 weeks of liraglutide treatment, insulin and HOMA-IR did not change. As shown in Figures 1 and 2, FI, VFV, and IHL were all significantly decreased after 12 and 24 weeks of treatment. FI was $14.8 \pm 4.4$ before treatment (baseline) and decreased to $13.7 \pm 3.9$ after 12 weeks of treatment, before falling further to $12.9 \pm 3.4 \mathrm{~kg} / \mathrm{m}^{2}$ at 24 weeks $(\mathrm{P}<0.05)$. VFV was $5,192 \pm 1,730$ at baseline, but was reduced to $4,653 \pm$ 1,468 after 12 weeks of treatment and to $4,513 \pm 1,299 \mathrm{~cm}^{3}$ at 24 weeks $(\mathrm{P}<0.05)$. In addition, IHL was $32.1 \pm 12.6$ at baseline, $18.4 \pm 7.7$ at 12 weeks, and $15.2 \pm 9.2 \%$ at 24 weeks $(\mathrm{P}<$ $0.01)$. In contrast, SMI was unchanged by liraglutide treatment $(9.7 \pm 1.5$ at baseline, $9.6 \pm 1.7$ at 12 weeks, and $9.4 \pm 1.2 \mathrm{~kg} /$ $\mathrm{m}^{2}$ at 24 weeks) and SFV was also unchanged (14,113 $\pm 4,856$ at baseline, 13,978 \pm 4,299 at 12 weeks, and 13,736 $\pm 3,537$ $\mathrm{cm}^{3} / \mathrm{kg}$ at 24 weeks). Thus, the SMI/FI ratio showed a significant increase after 24 weeks of treatment $(0.71 \pm 0.27$ at baseline vs. $0.76 \pm 0.26$ at 24 weeks, $\mathrm{P}<0.05)$. Individual changes of FI, SMI, and the SMI/FI ratio are listed in Table 2, while individual changes of VFV, SFV, and IHL are detailed in Table 3. Although there was a marked decrease of body fat, visceral fat, and intrahepatic fat in the majority of the patients, little or no improvement was noted in patient No. 3 and patient No. 7 .

\section{Discussion}

In the present study, administration of liraglutide $(0.9 \mathrm{mg}$ once daily for 24 weeks) to drug-naive obese Japanese patients with type 2 diabetes significantly decreased $\mathrm{HbA} 1 \mathrm{c}$ and also caused several changes of body composition. First, body weight (BW) and BMI were reduced from $103.4 \pm 14.7$ to $97.0 \pm 12.4 \mathrm{~kg}$ (mean reduction: $11.7 \%$ ) and from $37.4 \pm 6.4$ to $35.0 \pm 5.3$ $\mathrm{kg} / \mathrm{m}^{2}$ (mean reduction: $5.8 \%$ ), respectively. Second, VFV and IHL were reduced from $5,192 \pm 1,730$ to $4,513 \pm 1,299 \mathrm{~cm}^{3}$ (mean reduction: $11.9 \%$ ) and from $32.1 \pm 12.6 \%$ to $15.2 \pm 9.2 \%$ (mean reduction: $49.2 \%$ ), respectively, while there was no significant change of abdominal SFV. Third, DEXA revealed a decrease of FI from $14.8 \pm 4.4$ to $12.9 \pm 3.4 \mathrm{~kg} / \mathrm{m}^{2}$ (mean reduction: $10.9 \%$ ) and an increase of the SMI/FI ratio from $0.71 \pm 0.27$ to $0.78 \pm 0.26$ (mean increase: $10.3 \%$ ), with no significant change of SMI.

In the phase 3 trial of liraglutide monotherapy $(0.9 \mathrm{mg}$ once daily for 24 weeks) and the 52-week trial of combination therapy with oral antidiabetic agents in Japanese patients with type 2 diabetes, the reduction of BW was much smaller than in the present study $(0.92-1.58$ vs. $6.40 \mathrm{~kg})[14,15]$. This may be partly explained by differences in the baseline BMI of the patients $\left(24.5\right.$ - 26.7 vs. $\left.37.4 \mathrm{~kg} / \mathrm{m}^{2}\right)$, suggesting that greater reduction of BW by liraglutide can be expected in severely obese patients. In another trial of liraglutide (0.9 $\mathrm{mg}$ /day for 6 months) performed in Japanese patients with a

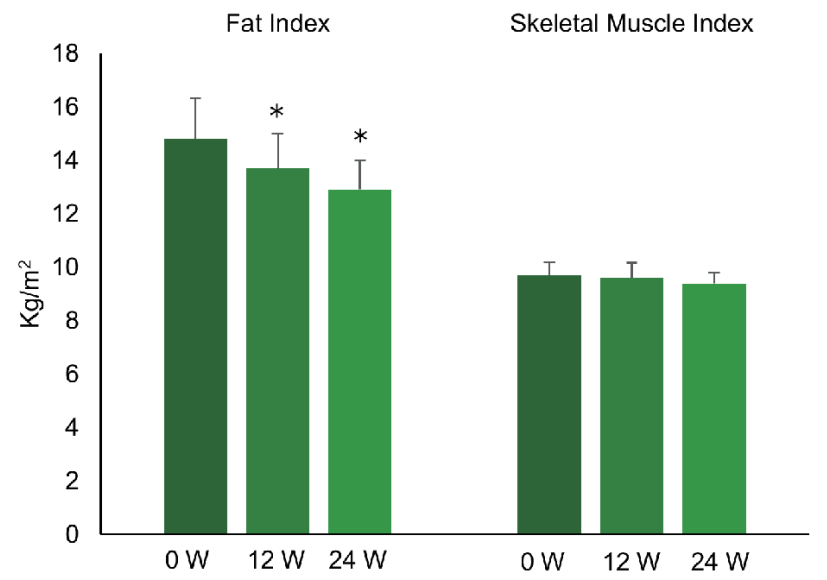

Figure 1. Changes of fat index and skeletal muscle index during the treatment with liraglutide $(0.9 \mathrm{mg} /$ day $)$ in obese Japanese patients with type 2 diabetes. ${ }^{*} \mathrm{P}<0.05$ versus 0 week. 


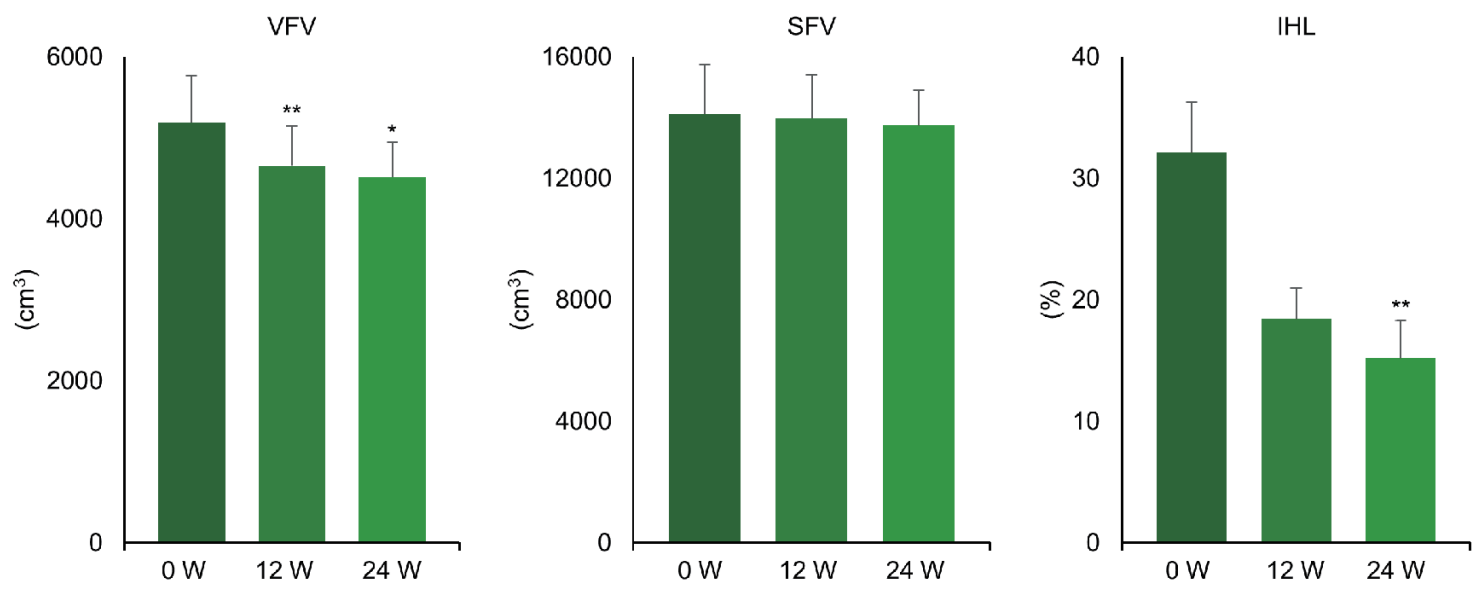

Figure 2. Changes of visceral fat volume, subcutaneous fat volume, and intrahepatic lipid content during the treatment with liraglutide $(0.9 \mathrm{mg} /$ day $)$ in obese Japanese patients with type 2 diabetes. ${ }^{*} P<0.05$, ${ }^{* *} P<0.01$ versus 0 week.

mean BMI of $29.7 \mathrm{~kg} / \mathrm{m}^{2}$, the mean BW was reduced from 80.8 to $78.0 \mathrm{~kg}[16]$. In the LEAD-3 trial, the mean BW of obese patients (mainly Caucasians) was decreased by $3.2 \mathrm{~kg}$ after 52 weeks of liraglutide monotherapy at $1.8 \mathrm{mg} /$ day [8]. Similarly, treatment with exenatide $(10 \mu \mathrm{g}$ twice daily for 26 weeks) achieved a mean reduction of BW by $5.5 \mathrm{~kg}$ in obese Caucasian patients with type 2 diabetes and a BMI $\geq 30 \mathrm{~kg} / \mathrm{m}^{2}$ [17]. Furthermore, administration of liraglutide for 56 weeks at $3.0 \mathrm{mg} /$ day achieved a mean reduction of BW by $8.4 \mathrm{~kg}$ in obese non-diabetic subjects with a BMI $\geq 30$, or $\geq 27 \mathrm{~kg} / \mathrm{m}^{2}$ if

Table 2. Individual Changes of Body Fat and Skeletal Muscle Indices After Treatment With Liraglutide for 24 Weeks

\begin{tabular}{|c|c|c|c|c|c|c|c|c|c|c|c|}
\hline $\begin{array}{l}\text { Patient } \\
\text { no. }\end{array}$ & Age & Sex & $\begin{array}{l}\text { Baseline } \\
\text { FI }\end{array}$ & $\begin{array}{l}\text { FI at } 24 \\
\text { weeks }\end{array}$ & $\begin{array}{l}\text { Change from } \\
\text { baseline (\%) }\end{array}$ & $\begin{array}{l}\text { Baseline } \\
\text { SMI }\end{array}$ & $\begin{array}{l}\text { SMI at } \\
24 \text { weeks }\end{array}$ & $\begin{array}{l}\text { Change from } \\
\text { baseline (\%) }\end{array}$ & $\begin{array}{l}\text { Baseline } \\
\text { SMI/FI }\end{array}$ & $\begin{array}{l}\text { SMI/FI at } \\
24 \text { weeks }\end{array}$ & $\begin{array}{l}\text { Change from } \\
\text { baseline }(\%)\end{array}$ \\
\hline 1 & 31 & M & 14.1 & 12.6 & -10.6 & 12.4 & 11.7 & -5.6 & 0.88 & 0.93 & 5.6 \\
\hline 2 & 57 & $\mathrm{~F}$ & 13.7 & 12.7 & -7.3 & 8.4 & 8.4 & 0 & 0.61 & 0.66 & 7.9 \\
\hline 3 & 51 & $\mathrm{M}$ & 6.6 & 6.3 & -4.5 & 8.8 & 8.6 & -2.3 & 1.33 & 1.37 & 2.4 \\
\hline 4 & 38 & $\mathrm{~F}$ & 21.1 & 18.9 & -10.4 & 10.5 & 10.1 & -3.8 & 0.49 & 0.53 & 7.4 \\
\hline 7 & 42 & $\mathrm{~F}$ & 11.9 & 12.4 & 4.2 & 7.2 & 7.4 & 2.8 & 0.61 & 0.6 & -1.4 \\
\hline 8 & 20 & $\mathrm{~F}$ & 19.8 & 15.8 & -20.2 & 10.1 & 9.1 & -9.9 & 0.51 & 0.58 & 12.9 \\
\hline 9 & 41 & M & 18.1 & 13.1 & -27.6 & 10.1 & 9.9 & -1.9 & 0.56 & 0.76 & 35.4 \\
\hline
\end{tabular}

Table 3. Individual Changes of Abdominal Fat Volume and Intrahepatic Lipid Content

\begin{tabular}{|c|c|c|c|c|c|c|c|c|c|c|c|}
\hline $\begin{array}{l}\text { Patient } \\
\text { no. }\end{array}$ & Age & Sex & $\begin{array}{l}\text { Baseline } \\
\text { VFV }\left(\mathrm{cm}^{3}\right)\end{array}$ & $\begin{array}{l}\text { VFV at } 24 \\
\text { weeks }\left(\mathrm{cm}^{3}\right)\end{array}$ & $\begin{array}{l}\text { Change from } \\
\text { baseline }(\%)\end{array}$ & $\begin{array}{l}\text { Baseline } \\
\text { SFV }\left(\mathrm{cm}^{3}\right)\end{array}$ & $\begin{array}{l}\text { SFV at } 24 \\
\text { weeks }\left(\mathrm{cm}^{3}\right)\end{array}$ & $\begin{array}{l}\text { Change from } \\
\text { baseline }(\%)\end{array}$ & $\begin{array}{l}\text { Baseline } \\
\text { IHL (\%) }\end{array}$ & $\begin{array}{l}\text { IHL at } 24 \\
\text { weeks }(\%)\end{array}$ & $\begin{array}{l}\text { Change from } \\
\text { baseline }(\%)\end{array}$ \\
\hline 1 & 31 & M & 5,590 & 4,776 & -14.6 & 15,266 & 14,442 & -5.4 & 24.7 & 2.7 & -88.9 \\
\hline 3 & 51 & M & 4,469 & 4,585 & 2.6 & 4,868 & 5,191 & -6.6 & 28.5 & 26.1 & -8.5 \\
\hline 4 & 38 & $\mathrm{~F}$ & 5,209 & 4,943 & -5.1 & 17,085 & 16,713 & 2.2 & 23.6 & 11.3 & -51.9 \\
\hline 7 & 42 & $\mathrm{~F}$ & 4,231 & 4,399 & 3.9 & 11,933 & 12,576 & 5.4 & 39.6 & 34.8 & -12.2 \\
\hline 8 & 20 & $\mathrm{~F}$ & 3,783 & 2,448 & -35.3 & 22,119 & 16,802 & -24.1 & 62.4 & 9.5 & -84.8 \\
\hline 9 & 41 & M & 9,713 & 7,576 & -22.1 & 16,433 & 13,817 & -15.9 & 35.1 & 18.7 & -46.7 \\
\hline
\end{tabular}


they had treated/untreated dyslipidemia or hypertension [18]. Thus, the BW-lowering effect of GLP-1RAs seems to be dependent on the baseline BMI and the dosage.

Human hepatocytes and adipocytes express the GLP-1 receptor, allowing GLP-1RAs to directly decrease hepatic steatosis and stimulate lipolysis by acting on these cells to promote reduction of IHL and VFV [19, 20]. A study by Dutour et al showed $23.81 \pm 9.5 \%$ reduction of IHL by ${ }^{1} \mathrm{H}-\mathrm{MRS}$ after treatment with exenatide [17]. In addition, Cuthbertson et al used ${ }^{1} \mathrm{H}-\mathrm{MRS}$ analysis to demonstrate a $42 \%$ reduction of IHL (interquartile range: $17-59 \%$ ) and an $11.2 \%$ reduction of VFV (interquartile range: 2.1-15.4\%) after 6 months of treatment with exenatide (10 $\mu \mathrm{g}$ twice daily) or liraglutide $(1.2 \mathrm{mg}$ once daily) in obese patients with a mean BMI of $38.4 \pm 5.6$ $\mathrm{kg} / \mathrm{m}^{2}$ [21]. Interestingly, they observed a smaller reduction of SFV (mean: $6.8 \%$ ) compared with VFV, although it was still significant. Recently, Bouchi et al reported significant reduction of hepatic fat (estimated from CT data) and the visceral fat area, but not the subcutaneous fat area, in Japanese patients receiving liraglutide at $0.9 \mathrm{mg}$ once daily for 24 weeks [22]. While these data suggest that GLP-1RAs preferentially reduce hepatic and visceral fat rather than subcutaneous fat, the reduction of visceral and subcutaneous fat was similar in the LEAD-2 trial [8]. Thus, further investigation is required to better define the possibly differing effects of GLP-1RAs on visceral and subcutaneous adipose tissue. As far as we know, the present study was the first to evaluate the effect of liraglutide on IHL by ${ }^{1} \mathrm{H}-\mathrm{MRS}$ analysis and on VFV by wholeabdominal CT scanning in obese Japanese patients with diabetes. Even with a lower dose of liraglutide, we observed similar marked reduction of IHL and VFV, but not SFV, to that reported previously.

Previous studies have showed that GLP-1RA therapy has a greater effect on body fat mass with less effect on muscle mass [8-11, 22], and the present findings were consistent with these reports. GLP-1RAs have been shown to directly activate glucose transport in mouse skeletal muscle cells and L6 myotubes by an AMPK-dependent mechanism [23, 24], but the non-insulinotropic effect of GLP-1RAs on glucose uptake by human skeletal muscle is not fully understood. Interestingly, it was reported that GLP-1 mediates an increase of microvascular blood flow and volume in human skeletal muscle, suggesting that it may increase the postprandial delivery of insulin, glucose, and amino acids to skeletal muscle, thus promoting muscle tissue synthesis and suppressing breakdown [25].

The present study was limited by its small sample size and single-arm design. Two patients showed little or no fat loss (Nos. 3 and 7), suggesting individual differences of the response to the lower dose of liraglutide $(0.9 \mathrm{mg})$ tested in this study. Thus, it is unsuitable to compare the present findings with the results of previous large-scale studies, and it is also difficult to discuss individual differences in the efficacy of liraglutide. Further large-scale studies will be required to confirm the present findings with regard to the positive effect of liraglutide on body composition in obese Japanese patients with type 2 diabetes.

In conclusion, administration of liraglutide $(0.9 \mathrm{mg}$ once daily for 24 weeks) to obese drug-naive Japanese patients with type 2 diabetes reduced body fat, especially visceral fat and intrahepatic fat, while having a less marked effect on skeletal muscle.

\section{Acknowledgments}

Not applicable.

\section{Financial Disclosure}

Not applicable.

\section{Conflict of Interest}

The authors declare no conflict of interest.

\section{Informed Consent}

Written informed consent was obtained from all patients.

\section{Author's Contribution}

All the authors have contributed significantly and have read the manuscript and have approved this submission.

\section{References}

1. Despres JP, Lemieux I. Abdominal obesity and metabolic syndrome. Nature. 2006;444(7121):881-887.

2. Yki-Jarvinen H. Non-alcoholic fatty liver disease as a cause and a consequence of metabolic syndrome. Lancet Diabetes Endocrinol. 2014;2(11):901-910.

3. Kim B, Tsujimoto T, So R, Zhao X, Oh S, Tanaka K. Changes in muscle strength after diet-induced weight reduction in adult men with obesity: a prospective study. Diabetes Metab Syndr Obes. 2017;10:187-194.

4. DeFronzo RA, Tripathy D. Skeletal muscle insulin resistance is the primary defect in type 2 diabetes. Diabetes Care. 2009;32(Suppl 2):S157-163.

5. Moore MC, Cherrington AD, Wasserman DH. Regulation of hepatic and peripheral glucose disposal. Best Pract Res Clin Endocrinol Metab. 2003;17(3):343-364.

6. Bolinder J, Ljunggren O, Kullberg J, Johansson L, Wilding J, Langkilde AM, Sugg J, et al. Effects of dapagliflozin on body weight, total fat mass, and regional adipose tissue distribution in patients with type 2 diabetes mellitus with inadequate glycemic control on metformin. J Clin Endocrinol Metab. 2012;97(3):1020-1031.

7. Ohta A, Kato H, Ishii S, Sasaki Y, Nakamura Y, Nakagawa T, Nagai Y, et al. Ipragliflozin, a sodium glucose cotransporter 2 inhibitor, reduces intrahepatic lipid content and abdominal visceral fat volume in patients with type 2 diabetes. Expert Opin Pharmacother. 2017;18(14):1433- 
1438.

8. Jendle J, Nauck MA, Matthews DR, Frid A, Hermansen K, During M, Zdravkovic M, et al. Weight loss with liraglutide, a once-daily human glucagon-like peptide-1 analogue for type 2 diabetes treatment as monotherapy or added to metformin, is primarily as a result of a reduction in fat tissue. Diabetes Obes Metab. 2009;11(12):11631172.

9. Perna S, Guido D, Bologna C, Solerte SB, Guerriero F, Isu A, Rondanelli M. Liraglutide and obesity in elderly: efficacy in fat loss and safety in order to prevent sarcopenia. A perspective case series study. Aging Clin Exp Res. 2016;28(6):1251-1257.

10. Blundell J, Finlayson G, Axelsen M, Flint A, Gibbons C, Kvist T, Hjerpsted JB. Effects of once-weekly semaglutide on appetite, energy intake, control of eating, food preference and body weight in subjects with obesity. Diabetes Obes Metab. 2017;19(9):1242-1251.

11. Nauck MA, Petrie JR, Sesti G, Mannucci E, Courreges JP, Lindegaard ML, Jensen CB, et al. A Phase 2, Randomized, Dose-finding study of the novel once-weekly human GLP-1 analog, semaglutide, compared with placebo and open-label liraglutide in patients with type 2 diabetes. Diabetes Care. 2016;39(2):231-241.

12. Tsukiyama H, Nagai Y, Matsubara F, Shimizu H, Iwamoto T, Yamanouchi E, Sada Y, et al. Proposed cut-off values of the waist circumference for metabolic syndrome based on visceral fat volume in a Japanese population. J Diabetes Investig. 2016;7(4):587-593.

13. Matsubara F, Nagai Y, Tsukiyama H, Shimizu H, Yamanouchi E, Iwamoto T, Sada Y, et al. Proposed cut-off value of the intrahepatic lipid content for metabolically normal persons assessed by proton magnetic resonance spectroscopy in a Japanese population. Diabetes Res Clin Pract. 2016;119:75-82.

14. Seino Y, Rasmussen MF, Nishida T, Kaku K. Efficacy and safety of the once-daily human GLP-1 analogue, litaglutide, vs. glibenclamide monotherapy in Japanese patients with type 2 diabetes. Curr Med Res Opin. 2010;12:341347.

15. Kiyosue A, Seino Y, Nishijima K, Bosch-Traberg H, Kaku K. Safety and efficacy of the combination of the glucagon-like peptide-1 receptor agonist liraglutide with an oral antidiabetic drug in Japanese patients with type 2 diabetes: Post-hoc analysis of a randomized, 52-week, open-label, parallel-group trial. J Diabetes Investig. 2018;9(4):831-839.

16. Suzuki D, Toyoda M, Kimura M, Miyauchi M, Yamamoto N, Sato H, Tanaka E, et al. Effects of liraglutide, a human glucagon-like peptide-1 analogue, on body weight, body fat area and body fat-related markers in patients with type 2 diabetes mellitus. Intern Med. 2013;52(10):1029-1034.

17. Dutour A, Abdesselam I, Ancel P, Kober F, Mrad G, Darmon P, Ronsin O, et al. Exenatide decreases liver fat content and epicardial adipose tissue in patients with obesity and type 2 diabetes: a prospective randomized clinical trial using magnetic resonance imaging and spectroscopy. Diabetes Obes Metab. 2016;18(9):882-891.

18. Pi-Sunyer X, Astrup A, Fujioka K, Greenway F, Halpern A, Krempf M, Lau DC, et al. A randomized, controlled trial of $3.0 \mathrm{mg}$ of liraglutide in weight management. N Engl J Med. 2015;373(1):11-22.

19. Gupta NA, Mells J, Dunham RM, Grakoui A, Saxena NK, Anaria FA. Glucagon-like peptide-1 receptor is present on human hepatocyte and has a direct role in decreasing hepatic steatosis in vitro by modulating elements of the insulin signaling pathway. Hepatology. 2010;51:15841592.

20. Vendrell J, El Bekay R, Peral B, Garcia-Fuentes E, Megia A, Macias-Gonzalez M, Fernandez Real J, et al. Study of the potential association of adipose tissue GLP-1 receptor with obesity and insulin resistance. Endocrinology. 2011;152(11):4072-4079.

21. Cuthbertson DJ, Irwin A, Gardner CJ, Daousi C, Purewal T, Furlong N, Goenka N, et al. Improved glycaemia correlates with liver fat reduction in obese, type 2 diabetes, patients given glucagon-like peptide-1 (GLP-1) receptor agonists. PLoS One. 2012;7(12):e50117.

22. Bouchi R, Nakano Y, Fukuda T, Takeuchi T, Murakami M, Minami I, Izumiyama $\mathrm{H}$, et al. Reduction of visceral fat by liraglutide is associated with ameliorations of hepatic steatosis, albuminuria, and micro-inflammation in type 2 diabetic patients with insulin treatment: a randomized control trial. Endocr J. 2017;64(3):269-281.

23. Li Z, Ni CL, Yao Z, Chen LM, Niu WY. Liraglutide enhances glucose transporter 4 translocation via regulation of AMP-activated protein kinase signaling pathways in mouse skeletal muscle cells. Metabolism. 2014;63(8):1022-1030.

24. Andreozzi F, Raciti GA, Nigro C, Mannino GC, Procopio T, Davalli AM, Beguinot F, et al. The GLP-1 receptor agonists exenatide and liraglutide activate Glucose transport by an AMPK-dependent mechanism. J Transl Med. 2016;14(1):229.

25. Abdulla H, Phillips B, Smith K, Wilkinson D, Atherton PJ, Idris I. Physiological mechanisms of action of incretin and insulin in regulating skeletal muscle metabolism. Curr Diabetes Rev. 2014;10(5):327-335. 